\title{
Microparticles in sputum of COPD patients: a potential biomarker of the disease?
}

\author{
This article was published in the following Dove Press journal: \\ International Journal of COPD \\ 14 March 2016 \\ Number of times this article has been viewed
}

\author{
Donato Lacedonial,* \\ Giovanna Elisiana \\ Carpagnano ${ }^{1, *}$ \\ Teresa Trotta ${ }^{2}$ \\ Grazia Pia Palladino' \\ Maria Antonietta Panaro 3 \\ Liugi Davide Zoppo' \\ Maria Pia Foschino \\ Barbaro' \\ Chiara Porro² \\ 'Department of Medical and Surgical \\ Sciences, Institute of Respiratory \\ Diseases, ${ }^{2}$ Department of Clinical and \\ Experimental Medicine, University \\ of Foggia, Foggia, ${ }^{3}$ Department of \\ Biosciences, Biotechnologies and \\ Biopharmaceutics, University of Bari, \\ Bari, Italy \\ *These authors contributed equally \\ to this work
}

Correspondence: Chiara Porro

Department of Clinical and Experimental Medicine, University of Foggia, Biomedical Research Center "E. Altomare" Via Napoli 20, 7 I I 00 Foggia, Italy

$\mathrm{Tel}+39$ 088I 588023

$\mathrm{Fax}+39088 I 588037$

Email chiara.porro@unifg.it
Background: Microparticles (MPs) are small membrane vesicles of $0.1-1 \mu \mathrm{m}$ which are released by cells following chemical, physical, and apoptotic stimuli. MPs represent more than a miniature version of the cell. Their composition and function depend not only on cellular origin, but also on stimuli. Chronic obstructive pulmonary disease (COPD) is a lung disease characterized by nearly irreversible lung destruction which results in airway limitation.

Purpose: We investigated the presence and source of MPs in sputum of COPD patients to evaluate if changes in MP number and origin may reflect the pathophysiological conditions of disease and may serve as potential biomarkers for diagnostic and prognostic use.

Methods: Induced sputum samples were collected from 18 male subjects and liquefied with Sputasol. MPs obtained were immunolabeled for leukocyte (CD11a), granulocyte (CD66b), monocyte-macrophage (CD11b), platelets and megakaryocytic cells (CD41), endothelial cells (CD31), and red blood cells (CD235ab) and analyzed by cytofluorimetry.

Results: There was a negative correlation between CD31-MPs and forced expiratory volume in 1 second $(R=-53, P<0.05)$ and CD66b-MP level was correlated with worse performance index of COPD such as the Body mass index airflow Obstruction, Dyspnea, and Exercise capacity (BODE); they were negatively correlated with 6-minute walking test: 0.65 and -0.64 , respectively $(P<0.05)$. CD235ab-MPs showed a negative correlation with body mass index $(R=-0.86$, $P<0.05)$, while there was a positive correlation with dyspnea index $(R=0.91, P<0.05)$.

Conclusion: The main finding of this study was that MPs were detected in the sputum of patients affected by COPD. The phenotype of some of them was related to the main COPD parameters. These results suggest that MPs could be implicated in the pathogenesis of COPD.

Keywords: COPD, microparticles, sputum, lung

\section{Background}

Extracellular vesicles have received a great deal of attention during the last decade as a novel approach to detect diseases as messengers or mediators of disease pathophysiology. The main classes of extracellular vesicles generally include exosomes, microvesicles/microparticles (MPs), and apoptotic bodies, which are differentiated by their biogenesis and secretion mechanisms. Exosomes are 50-150 nm in diameter and are characterized by their endosomal origin. Exosomes are released by endocytosis following intracellular assembly in multivesicular bodies that contain intraluminal vesicles.

MPs are shed from the plasma membrane through direct outward budding, and they are larger than exosomes (100-2,000 nm). MPs are enriched in phosphatidylserine and contain a membrane component that is similar to that of the parent cell membrane. ${ }^{1}$ Apoptotic bodies are $1-4 \mu \mathrm{m}$ in diameter and are released from the plasma membrane as blebs of cells undergo apoptosis. Apoptotic bodies may contain DNA 
fragments, noncoding RNAs, and cell organelles. ${ }^{2}$ Several cell types (such as macrophages, platelets, endothelial cells, granulocytes, monocytes, lymphocytes) release MPs following chemical (cytokines, thrombin, and endotoxin), physical (shear stress and hypoxia), and apoptotic stimuli. MPs play an active role in the initiation and amplification of the coagulation cascade, and a pivotal role has been proposed for them in thrombosis, propagating inflammation, modulating vascular tone, angiogenesis, stem cell engraftment, and tumor metastasis. ${ }^{3}$ MPs have been isolated from different biological fluids including plasma, ${ }^{4}$ serum,${ }^{5}$ cerebrospinal fluid, ${ }^{6}$ bronchoalveolar lavage, ${ }^{7}$ and synovial fluid. ${ }^{8}$

The phenotype of circulating MPs and, consequently, their origin are different in various pathological conditions, and detection of their cellular origin may serve as a predictor or marker of diseases. ${ }^{9}$

MPs are more than just a miniature version of the specific cell of origin, although the antigens found on the surface of MPs and their cargo resemble those of their parental cells (eg, lineage markers), as certain MP components are selectively enriched compared to their parental cell.

Recent reports have underlined their role as signaling elements in cell-cell communication. Interest has been attracted to MPs because of their positive correlations with various vascular diseases, but now investigation is also being made of MPs in pulmonary diseases in view of their amplified numbers, procoagulant properties, and participation in inflammatory events.

Many studies have been conducted in order to characterize circulating MPs in pulmonary diseases. Mutschler et al showed, for the first time ever, the presence of MPs, derived from platelets, in pulmonary air-liquid interfaces in sedated pigs. ${ }^{8}$ Recent investigations conducted in bronchoalveolar lavage fluid characterized intra-alveolar procoagulant MPs in patients with acute respiratory distress syndrome and hydrostatic pulmonary edema. In acute respiratory distress syndrome patients, intra-alveolar MPs contain high levels of tissue factor, show a highly procoagulant activity, and likely contribute to intra-alveolar fibrin formation, a critical pathogenic feature of acute lung injury. ${ }^{10,11}$

Chronic obstructive pulmonary disease (COPD) is a lung disease characterized by irreversible lung destruction which results in airflow limitation. The severity of the disease depends largely on the degree of airflow limitation, which is measured by forced expiratory volume in 1 second $\left(\mathrm{FEV}_{1}\right){ }^{12}$

In 2010, Porro et $\mathrm{al}^{13}$ provided evidence of the presence of MPs in sputum obtained from cystic fibrosis patients and also found that MPs obtained from cystic fibrosis sputum are proinflammatory when injected into the lungs of mice. ${ }^{14}$

The goal of the present study is to investigate the presence and source of sputum MPs in COPD patients and to correlate the number and source of MPs to the clinical picture. Changes in MP number and composition may reflect the disease pathophysiological conditions and, therefore, could have potential prognostic value for diagnostic use. Understanding MP involvement in COPD may provide insight into disease mechanisms and also aid in the development of novel therapeutic strategies.

\section{Methods}

\section{Study patients}

The study was approved and performed according to the ethical standards of CE Azienda Ospedaliero-Universitaria Ospedali Riuniti di Foggia on human experimentation. Written informed consent was obtained from each subject.

Induced sputum samples were collected from 18 male subjects with mild to severe COPD (I-IV stages according to Global initiative for chronic Obstructive Lung Disease guidelines) enrolled at the Institute of Respiratory diseases (Ospedali Riuniti of Foggia). All subjects were former smokers, and stopped smoking for at least 1 year. Presence of main comorbidities was also evaluated and it was found that the majority of patients had been affected by cardiovascular diseases (Table 1). All subjects completed the study questionnaires on smoking status, COPD Assessment Test score, and general data, and performed standardized spirometry. The equipment was calibrated daily using a $3 \mathrm{~L}$ syringe. In accordance with the Global initiative for chronic Obstructive Lung Disease guidelines, the subjects were defined as $\mathrm{COPD}$ when $\mathrm{FEV}_{1}$ /forced vital capacity was $<70 \%$ postbronchodilation. All patients with COPD had stable disease with no exacerbation or respiratory tract infection 2 months before the study. Drugs for COPD (inhaled corticosteroid/ long-acting $\beta 2$-agonist or long-acting muscarinic antagonist) were interrupted at least 7 days before the collection of sputum. The data about the 6-minute walking test (6MWT), and body mass index (BMI), and dyspnea by Borg scale ${ }^{15}$ were also collected, and the BODE index was then calculated according to international guidelines were also calculated according to international guidelines. ${ }^{16}$

\section{Collection of sputum samples}

Sputum induction was achieved by making the patients inhale hypertonic saline solution via UltraNeb DevilBiss (Sunrise Medical, Wollaston, UK) treated with Sputasol (Oxoid, 
Table I General characteristics of COPD patients at enrollment in the study

\begin{tabular}{|c|c|c|}
\hline & Mean & SD \\
\hline Age (years) & 70.33 & 8.98 \\
\hline $\mathrm{BMI}\left(\mathrm{kg} / \mathrm{m}^{2}\right)$ & 28.39 & 5.10 \\
\hline Pack/years & 39.13 & 20.34 \\
\hline $\mathrm{FEV}_{1} / \mathrm{FVC}$ & 50.83 & 15.21 \\
\hline $\mathrm{FEV}_{1}(\%)$ & 52.39 & 22.19 \\
\hline FVC (\%) & 81.28 & 23.44 \\
\hline GOLD stage I (N) & 3 & \\
\hline GOLD stage II (N) & 7 & \\
\hline GOLD stage III (N) & 4 & \\
\hline GOLD stage IV (N) & 4 & \\
\hline $\mathrm{mMRC}$ & 2.46 & 1.81 \\
\hline Borg & 11.00 & 3.51 \\
\hline Number of exacerbations & 1.69 & 0.63 \\
\hline BODE index & 2.64 & 1.96 \\
\hline 6MWT (m) & 326.08 & 103.40 \\
\hline $\mathrm{pH}$ & 7.41 & 0.03 \\
\hline $\mathrm{paCO}_{2}(\mathrm{mmHg})$ & 45.49 & 8.33 \\
\hline $\mathrm{paO}_{2}(\mathrm{mmHg})$ & 64.43 & 11.61 \\
\hline $\mathrm{HCO}_{3}(\mathrm{mEq})$ & 28.34 & 5.84 \\
\hline $\mathrm{SaO}_{2}(\%)$ & 92.46 & 6.11 \\
\hline Hypertension (\%) & 22 & \\
\hline Heart diseases (\%) & 44 & \\
\hline Diabetes (\%) & II & \\
\hline Others diseases (\%) & 28 & \\
\hline
\end{tabular}

Abbreviations: 6MWT, 6-minute walking test; $\mathrm{BMI}$, body mass index; BODE, Body mass index airflow Obstruction, Dyspnea, and Exercise capacity; COPD, chronic obstructive pulmonary disease; FEV , forced expiratory volume in I second; FVC, forced vital capacity; GOLD, Global initiative for chronic Obstructive Lung Disease; mMRC, modified Medical Research Council scale for dyspnea; SD, standard deviation.

Hampshire, UK) according to European Respiratory Society guidelines. ${ }^{17}$ The whole expectorate was collected directly into a clear plastic Petri dish where the selection process was performed. We used forceps to pull the sputum out of the surrounding saliva. The selected sputum (plugs) was dissolved in Sputasol. After homogenization, the solution was filtered through a nylon mesh filter ( $53 \mu$ m nylon mesh).

The filtered cell suspension was centrifuged at $600 \times g$ for 10 minutes at $4^{\circ} \mathrm{C}-8^{\circ} \mathrm{C}$, and the supernatant was aspirated and stored at $-80^{\circ} \mathrm{C}$ for the analysis of MPs, performed later. The total cell count and viability of sputum cells were obtained simultaneously in a Bürker counting chamber. Cytospins were prepared, stained with Diff Quick Stain (Medion Diagnostics, Düdingen, Switzerland), and two researchers with training in reading induced sputum slides independently counted 400 nonsquamous cells on the stained slides.

\section{MP isolation}

The processed sputum was centrifuged at $37 \times g$ for 3 minutes. The supernatant was then centrifuged at $253 \times g$ for 10 minutes and recentrifuged at $253 \times g$ for 20 minutes to remove the cells and large debris, respectively. Two hundred microliters of each MP-containing supernatant was frozen and stored at $-80^{\circ} \mathrm{C}$ until characterization by flow cytometry.

\section{MP characterization}

The MP population was characterized in the sputum supernatant according to the expression of membrane-specific antigens. Antihuman CD11a labeling was used to count leukocyte MPs, while counting of granulocyte MPs was performed using antihuman CD66b. Platelets and megakaryocytic MPs were counted using antihuman CD41, platelet-endothelial MPs (EMPs) using antihuman CD31, and MPs from red blood cells were counted using antihuman CD235ab. Human Immunoglobulin $M$ was used as isotype-matched negative control for CD66b, IgG1 was used as isotype-matched negative control for CD11a, CD41, and $\mathrm{CD} 31$, while IgG2 was the negative control for CD235ab. For these studies, $10 \mu \mathrm{L}$ of supernatant MPs was incubated with $10 \mu \mathrm{L}$ of specific antibody $(1 \mu \mathrm{g} / \mathrm{mL}$; fluorescein isothiocyanate conjugated; BioLegend, San Diego, CA, USA). After 15 minutes of incubation at $+4^{\circ} \mathrm{C}$, the samples were diluted in $500 \mu \mathrm{L}$ of $0.9 \%$ saline solution. Then, $10 \mu \mathrm{L}$ of flow count beads were added to each sample and analyzed in a flow cytometer (Beckman Coulter Epics XL-MCL, Miami, FL, USA). Sample analysis was stopped after counting 10,000 events.

\section{Statistical analysis}

All data are reported as mean \pm standard deviation and analyzed by Statistica Software (StatSoft, Inc, Tulsa, OK, USA). Continuous data are presented as mean \pm standard deviation in the tables. The relationships between variables were determined by measuring the Pearson's correlation coefficient or Spearman's correlation for the variables which were not normally distributed. A $P$-value of $<0.05$ was considered statistically significant.

\section{Results \\ Patients}

Patient characteristics are summarized in Table 1. Study participants were aged between 51 and 85 years and had a mean $\mathrm{FEV}_{1}$ of $52.39 \% \pm 22.19 \%$. Induced sputum was characterized by a high level of neutrophils $(86.33 \% \pm 13.98 \%)$ and although in two patients we found a higher number of eosinophils, in both cases, the level was lower than $10 \%$, while the prevalence of neutrophils was higher than $85 \%$ (Table 2). 
Table 2 Cellularity of induced sputum in COPD patients

\begin{tabular}{lll}
\hline & Mean & SD \\
\hline Eosinophils (\%) & 5.00 & 4.18 \\
Neutrophils (\%) & 86.33 & 13.98 \\
Macrophages (\%) & 10.33 & 13.54 \\
Lymphocytes (\%) & 0.67 & 0.58 \\
\hline
\end{tabular}

Abbreviations: COPD, chronic obstructive pulmonary disease; SD, standard deviation.

\section{MP phenotype}

MPs were found in induced sputum of all 18 subjects enrolled. The MP phenotype was analyzed by evaluating the presence of different antigens representing all cell types. The expression of CD66b-MPs (granulocytes) was higher than that of other MPs, CD235ab (erythrocytes), and CD31MPs (platelets/endothelial cell adhesion molecules 1) were also frequently found, instead the levels of CD41-MPs and CD11a-MPs were generally low (Table 3).

\section{Correlation between main COPD parameters and MP phenotype}

Table 4 summarizes the correlations between the MP phenotype and the main COPD parameters.

There was a negative correlation between CD31-MPs and $\mathrm{FEV}_{1}(R=-0.53, P<0.05$; Figure 1$)$. CD66b-MPs were correlated with a worse COPD performance index, being positively correlated with the BODE index and negatively correlated with 6MWT: 0.65 and -0.64 , respectively $(P<0.05)$. CD235ab-MPs showed a negative correlation with BMI $(R=-0.86, P<0.05)$ and a positive correlation with dyspnea index $(R=0.91, P<0.05)$. CD41-MPs and CD11aMPs did not show correlations with the other parameters analyzed (data not shown).

Finally, no correlation was found between the number of MPs and induced sputum cellularity, or with the number of disease exacerbations.

\section{Discussion}

The main result of the present study is the demonstration that in the sputum of patients affected by COPD, it is also

Table 3 Characterization of MPs in COPD sputum

\begin{tabular}{lll}
\hline & Mean & SD \\
\hline MPs $\left(\times 10^{3}\right) / \mu L$ & 20.02 & 27.09 \\
Cells $/ \mathrm{mL}$ in sputum $\left(\times 10^{6}\right)$ & 1.18 & 0.21 \\
CD66b-MPs $(\%)$ & 37.70 & 28.89 \\
CDIIa-MPs (\%) & 4.42 & 13.14 \\
CD4I-MPs (\%) & 7.71 & 7.82 \\
CD3I-MPs (\%) & 14.52 & 12.95 \\
CD235ab-MPs (\%) & 19.86 & 21.86 \\
\hline
\end{tabular}

Abbreviations: COPD, chronic obstructive pulmonary disease; MPs, microparticles; $\mathrm{SD}$, standard deviation.
Table 4 Main correlations between the MP phenotype and some COPD characteristics

\begin{tabular}{llll}
\hline$\%$ & CD66b-MPs & CD3 I-MPs & CD235ab-MPs \\
\hline BMI & 0.01 & -0.34 & $-0.86^{*}$ \\
FEV $\%$ & 0.28 & $-0.53^{*}$ & -0.45 \\
Borg & 0.24 & -0.46 & $0.9 I^{*}$ \\
BODE & $0.65^{*}$ & -0.08 & -0.09 \\
WT (m) & $-0.64^{*}$ & 0.25 & 0.39 \\
Neutrophils & 0.43 & 0.19 & 0.21 \\
Macrophages & -0.54 & -0.05 & -0.08 \\
Eosinophils & 0.43 & -0.42 & 0.27 \\
\hline
\end{tabular}

Note: $* P<0.05$.

Abbreviations: BMI, body mass index; BODE, Body mass index airflow Obstruction, Dyspnea, and Exercise capacity; COPD, chronic obstructive pulmonary disease; $\mathrm{FEV}_{1}$, forced expiratory volume in I second; MPs, microparticles; WT, walking test.

possible to detect the presence of MPs. The MPs were obtained with the same protocol used in a previous study ${ }^{13}$ and they were identified through measures of cytofluorimetric analysis.

The phenotype of some MPs is related with the main COPD parameters such as $\mathrm{FEV}_{1}$, BODE index, or 6MWT. These results, together with other data, suggest that MPs are likely implicated in the pathogenesis of COPD.

There are various subtypes of MPs that are defined according to specific membrane antigens, such as endothelial/ platelet cell adhesion molecule 1 (CD31), leukocytes (CD11a), megakaryocytic (CD41), granulocytes (CD66b), monocyte-macrophages (CD11b), and red blood cells (CD235ab), which have recently been described in a number of diseases including pulmonary hypertension and acute coronary syndrome. ${ }^{18}$

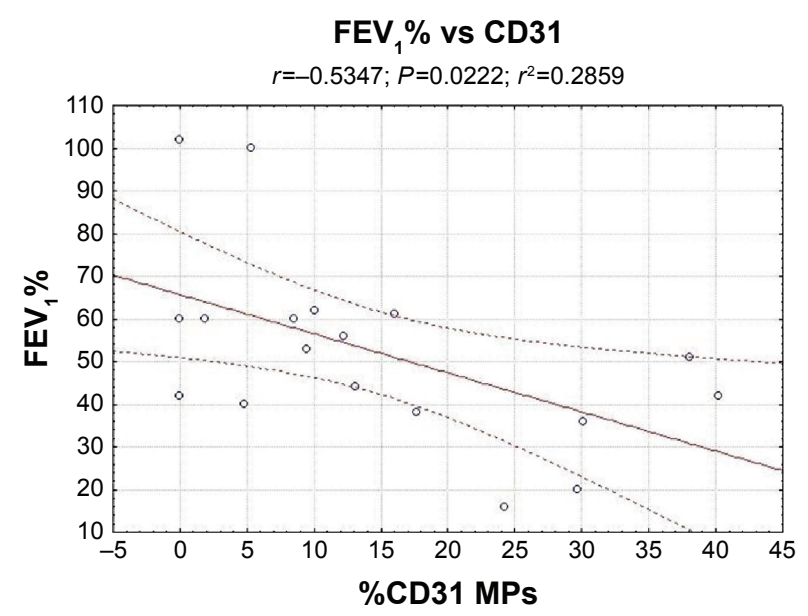

Figure I Correlation between $\mathrm{FEV}, \%$ and $\mathrm{CD} 3 \mathrm{I}$-microparticles.

Note: COPD patients with a worse lung function have higher levels of CD3I-MPs in sputum.

Abbreviations: COPD, chronic obstructive pulmonary disease; $\mathrm{FEV}_{1}$, forced expiratory volume in I second; MPs, microparticles. 
Different MPs were found in induced sputum of all patients enrolled; the levels of CD41-MPs and CD11a-MPs were low, CD235ab-MPs and CD31-MPs were frequently found, and CD66b-MPs were the most abundant among all other MPs.

No correlation was found between the number of MPs and induced sputum cellularity, as well as the number of exacerbations. This could mean that MPs were not strictly derived from sputum cells or influenced by exacerbations.

Platelet/endothelial cell adhesion molecule 1 (CD31) is a signaling molecule that plays various roles in vascular biology, in particular, in the regulation of platelet function, angiogenesis, T- and B-cell activation, endothelial cell permeability, and transmigration across the endothelium. ${ }^{19-24}$ PECAM-1 is concentrated at endothelial junctions and is also expressed on the surface of platelets, neutrophils, and subsets of lymphocytes. Unlike vascular endothelial-cadherin, PECAM-1 is located outside the adherence junctions on endothelial cells. ${ }^{25}$

Takahashi et $\mathrm{al}^{26}$ reported that CD31-EMPs are released from pulmonary microvascular endothelial cells mainly in response to apoptosis induced by stimulation by $\mathrm{H}_{2} \mathrm{O}_{2}$ or cigarette smoke extract.

Thus, the released EMPs likely reflect the apoptosis of injured endothelial cells. ${ }^{6}$ In a recent paper, Thomashow et a ${ }^{27}$ demonstrated that circulating levels of CD31-MPs were higher in COPD patients compared to control subjects and, moreover, that there was a negative correlation with $\mathrm{FEV}_{1}$ and with the percentage of emphysema. Liu et $\mathrm{al}^{28}$ also found a relationship between $\mathrm{CD} 31^{+}$and the severity of obstruction in animal models.

In our study, we found high levels of CD31-MPs also, in the sputum of COPD patients, the numbers being negatively correlated with the severity of disease. Patients with a worse lung function have highest levels of CD31-MPs (Figure 1).

Thus, we can hypothesize that CD31-MPs could be directly correlated with lung damage; in fact, these data indicate that the high levels of circulating and local MPs could reflect the decline of small airway function in COPD patients. Moreover, the presence of CD31-MPs in sputum could hypothesize lung epithelium and vascular endothelium damage in COPD patients.

On the other hand, CD66b-MPs and CD235ab-MPs were more strongly correlated with a worsening of the main COPD indexes such as BODE and 6MWT. Moreover, CD235ab-MPs showed a negative correlation with BMI and a positive correlation with dyspnea index. In this case, it is more difficult to explain the relationship with MPs because they are multiparametric indexes and, therefore, different components could be involved in their decline. We can only suppose that during the progression of disease, endothelial activations are increased, and this mechanism could upregulate the expression of a pool of MPs, including CD66b and CD235ab. However, clinical relevance of these correlations should be evaluated in future larger studies.

Recent studies, in fact, demonstrated that the main causes of death in COPD patients are not respiratory events, but cardiovascular events such as ischemic heart disease and stroke. ${ }^{29}$ Vascular abnormalities in the endothelium have been reported in both pulmonary ${ }^{30}$ and systemic vasculatures ${ }^{31}$ in COPD patients. Impaired endothelial function, as assessed by flow-mediated dilation of the brachial artery, is associated with a low FEV ${ }_{1}$ in COPD patients. ${ }^{6,32}$ Endothelial injury in the pulmonary capillary vasculature leads to lung destruction, and since cardiovascular diseases are the main cause of death among individuals with COPD, EMPs are now receiving attention as potential biomarkers for COPD.

The number of circulating EMPs is increased in patients with vascular disorders, such as acute coronary disease, ${ }^{33,34}$ renal failure, ${ }^{35}$ and metabolic diseases, ${ }^{36}$ and reflects the endothelial damage occurring in these patients. Moreover, the number of EMPs is a sensitive marker of pulmonary capillary endothelial damage induced by smoking in healthy active smokers. ${ }^{37}$

The number of apoptotic epithelial and endothelial cells is increased in emphysematous lung as compared to normal lung. ${ }^{38}$ The senescence of alveolar epithelial and endothelial cells is accelerated in patients with emphysema. ${ }^{39}$ Greater numbers of apoptotic lung cells are observed in lung tissues from COPD patients than in those from smokers without COPD ${ }^{40-42}$ Furthermore, morphological and biochemical markers of autophagy are increased in the lungs of patients with COPD compared with normal lung tissue. These results indicate the importance of injured cells in the pathophysiology of lung destruction and COPD. ${ }^{6}$

MPs are not passive agents induced from activated or injured cells, but rather active modulators that promote both proinflammatory and anti-inflammatory signals.$^{43} \mathrm{MPs}$ contain proteins and microRNAs and can deliver those components to distant endothelial cells. ${ }^{44}$ Therefore, increased EMPs may influence vascular function and systemic inflammation under COPD exacerbation. ${ }^{17}$

Increased DNA fragmentation in the pulmonary capillaries and arteriolar endothelium of individuals with COPD was shown by Segura-Valdez et al. ${ }^{45}$ In addition, Kasahara et a ${ }^{38,46,47}$ reported increased septal cell death (endothelial and epithelial cells) in human emphysematous lungs compared with lungs of nonsmokers or smokers without emphysema. ${ }^{37}$ 


\section{Conclusion}

The main result of our study is not only the presence of MPs in COPD patients' sputum, but also the relation between the number of EMPs and $\mathrm{FEV}_{1}$. This indicates that endothelial injury is closely connected to the pathophysiology of COPD.

Since COPD is a heterogeneous disease characterized by various combinations with small airway disease and emphysema, the relationships between the severity of the emphysema and the EMP count are of great interest. Moreover, as quicker responses can be seen in circulating EMP levels compared with an annual $\mathrm{FEV}_{1}$ decline, monitoring EMP levels is valuable as a means of estimating COPD progression.

Simple and noninvasive biomarkers in COPD are needed to monitor disease progression, identify exacerbations, and evaluate the efficacy of novel therapies. Sputum is a rich, noninvasive source of biomarkers of inflammation and infection, and has been used extensively to assess inflammation in lung airways pathologies. The presence of CD31-MPs in COPD sputum could be a new noninvasive method to monitor the disease course.

Main limitations of this study are that only a limited number of subjects with lung diseases were enrolled, so it was not possible to evaluate different expression of MPs according to severity of the disease, as well as the obvious absence of a control group with healthy subjects in whom it would be difficult to obtain sputum even if induced. However, our preliminary data suggest that high levels of MPs reflect the presence of endothelial inflammation. CD31-MPs, CD66b-MPs, and CD235ab-MPs could be good new candidates for the study of pulmonary endothelial injury and COPD progression.

Future studies could aim to evaluate if different stages of diseases can influence the phenotype of MPs and define the possible role of them in monitoring the effectiveness of medication.

\section{Acknowledgments}

We thank Prof MC Martinez for careful and critical reading of the manuscript. This work was supported by a grant of Foggia University (Fondo per i Progetti di Ricerca di Ateneo, PRA).

\section{Author contributions}

All authors contributed toward data analysis, drafting and critically revising the paper and agree to be accountable for all aspects of the work.

\section{Disclosure}

The authors report no conflicts of interest in this work.

\section{References}

1. Raposo G, Stoorvogel W. Extracellular vesicles: exosomes, microvesicles, and friends. J Cell Biol. 2013;200(4):373-383.

2. Beyer C, Pisetsky DS. The role of microparticles in the pathogenesis of rheumatic diseases. Nat Rev Rheumatol. 2010;6(1):21-29.

3. Benameur T, Andriantsitohaina R, Martínez MC. Therapeutic potential of plasma membrane derived microparticles. Pharmacol Rep. 2009;61(1):49-57.

4. Sinning JM, Losch J, Walenta K, Böhm M, Nickenig G, Werner N. Circulating CD31+/AnnexinV+ microparticles correlate with cardiovascular outcomes. Eur Heart J. 2011;32(16):2034-2041.

5. Baka Z, Senolt L, Vencovsky J, et al. Increased serum concentration of immune cell derived microparticles in polymyositis/dermatomyositis. Immunol Lett. 2010;128(2):124-130.

6. Morel N, Morel O, Petit L, et al. Generation of procoagulant microparticles in cerebrospinal fluid and peripheral blood after traumatic brain injury. J Trauma. 2008;64(3):698-704.

7. Mutschler DK, Larsson AO, Basu S, Nordgren A, Eriksson MB. Effects of mechanical ventilation on platelet microparticles in bronchoalveolar lavage fluid. Thromb Res. 2002;108(4):215-220.

8. Boilard E, Nigrovic PA, Larabee K, et al. Platelets amplify inflammation in arthritis via collagen-dependent microparticle production. Science. 2010;327(5965):580-583.

9. Martínez MC, Tesse A, Zobairi F, et al. Shed membrane microparticles from circulating and vascular cells in regulating vascular function. $\mathrm{Am}$ J Physiol Heart Circ Physiol. 2005;288(3):H1004-H1009.

10. Bastarache JA, Fremont RD, Kropski JA, Bossert FR, Ware LB. Procoagulant alveolar microparticles in the lungs of patients with acute respiratory distress syndrome. Am J Physiol Lung Cell Mol Physiol. 2009;297(6):L1035-L1041.

11. Takahashi T, Kubo H. The role of microparticles in chronic obstructive pulmonary disease. Int J Chron Obstruct Pulmon Dis. 2014;9: 303-314.

12. Takahashi T, Kobayashi S, Fujino N, et al. Increased circulating endothelial microparticles in COPD patients: a potential biomarker for COPD exacerbation susceptibility. Thorax. 2012;67(12):1067-1074.

13. Porro $\mathrm{C}$, Lepore $\mathrm{S}$, Trotta $\mathrm{T}$, et al. Isolation and characterization of microparticles in sputum from cystic fibrosis patients. Respir Res. 2010; 11:94.

14. Porro C, Di Gioia S, Trotta T, et al. Pro-inflammatory effect of cystic fibrosis sputum microparticles in the murine lung. J Cyst Fibros. 2013; 12(6):721-728.

15. Borg GA, Psychophysical bases of perceived exertion. Med Sci Sports Excerc. 1982;14(5):377-381.

16. Celli BR, Cote CG, Marin JM, et al. The Bode Mass Index, airflow obstruction, dyspnea, and exercise capacity index in chronic obstructive pulmonary disease. $N$ Engl J Med. 2004;350(10):1005-1012

17. Djukanović R, Sterk PJ, Fahy JV, et al. Standardised methodology of sputum induction and processing. Eur Respir J Suppl. 2002;37:1s-2s.

18. Amabile N, Heiss C, Chang V, et al. Increased CD62e(+) endothelial microparticle levels predict poor outcome in pulmonary hypertension patients. J Heart Lung Transplant. 2009;28(10):1081-1086.

19. Ley K, Laudanna C, Cybulsky MI, Noursharqh S. Getting to the site of inflammation: the leukocyte adhesion cascade updated. Nat Rev Immunol. 2007;7(9):678-689.

20. Patil S, Newman DK, Newman PJ. Platelet endothelial cell adhesion molecule-1 serves as an inhibitory receptor that modulates platelet responses to collagen. Blood. 2001;97(6):1727-1732

21. Cicmil M, Thomas JM, Leduc M, Bon C, Gibbins JM. Platelet endothelial cell adhesion molecule-1 signaling inhibits the activation of human platelets. Blood. 2002;99(1):137-144. 
22. Falati S, Patil S, Gross PL, et al. Platelet PECAM-1 inhibits thrombus formation in vivo. Blood. 2006;107(2):535-541.

23. Muller WA. Leukocyte-endothelial-cell interactions in leukocyte transmigration and the inflammatory response. Trends Immunol. 2003; 24(6):327-334.

24. Woodfin A, Voisin MB, Nourshargh S. PECAM-1: a multi-functional molecule in inflammation and vascular biology. Arterioscler Thromb Vasc Biol. 2007;27(12):2514-2523.

25. Newman PJ, Berndt MC, Gorski J, et al. PECAM-1 (CD31) cloning and relation to adhesion molecules of the immunoglobulin gene superfamily. Science. 1990;247(4947):1219-1222.

26. Takahashi T, Kobayashi S, Fujino N, et al. Differences in the released endothelial microparticle subtypes between human pulmonary microvascular endothelial cells and aortic endothelial cells in vitro. Exp Lung Res. 2013;39(4-5):155-161.

27. Thomashow MA, Shimbo D, Parikh MA, et al. Endothelial microparticles in mild chronic obstructive pulmonary disease and emphysema. The multi-ethnic study of atherosclerosis chronic obstructive pulmonary disease study. Am J Respir Crit Care Med. 2013;188(1):60-68.

28. Liu H, Ding L, Zhang Y, et al. Circulating endothelial microparticles involved in lung function decline in a rat exposed in cigarette smoke maybe from apoptotic pulmonary capillary endothelial cells. J Thorac Dis. 2014;6(6):649-655.

29. Young RP, Hopkins R, Eaton TE. Forced expiratory volume in one second: not just a lung function test but a marker of premature death from all causes. Eur Respir J. 2007;30(4):616-622.

30. Peinado VI, Pizarro S, Barberà JA. Pulmonary vascular involvement in COPD. Chest. 2008;134(4):808-814

31. Hunninghake DB. Cardiovascular disease in chronic obstructive pulmonary disease. Proc Am Thorac Soc. 2005;2(1):44-49.

32. Barr RG, Mesia-Vela S, Austin JH, et al. Impaired flow-mediated dilation is associated with low pulmonary function and emphysema in ex-smokers: the emphysema and cancer action project (EMCAP) study. Am J Respir Crit Care Med. 2007;176(12):1200-1207.

33. Nozaki T, Sugiyama S, Koga H, et al. Significance of a multiple biomarkers strategy including endothelial dysfunction to improve risk stratification for cardiovascular events in patients at high risk for coronary heart disease. J Am Coll Cardiol. 2009;54(7):601-608.

34. Lackner P, Dietmann A, Beer R, et al. Cellular microparticles as a marker for cerebral vasospasm in spontaneous subarachnoid hemorrhage. Stroke. 2010;41(10):2353-2357.

35. Amabile N, Guérin AP, Leroyer A, et al. Circulating endothelial microparticles are associated with vascular dysfunction in patients with end-stage renal failure. J Am Soc Nephrol. 2005;16(11):3381-3388.
36. Pirro M, Schillaci G, Paltriccia R, et al. Increased ratio of CD31+/ CD42- microparticles to endothelial progenitors as a novel marker of atherosclerosis in hypercholesterolemia. Arterioscler Thromb Vasc Biol. 2006;26(11):2530-2535.

37. Gordon C, Gudi K, Krause A, et al. Circulating endothelial microparticles as a measure of early lung destruction in cigarette smokers. Am J Respir Crit Care Med. 2011;184(2):224-232.

38. Kasahara Y, Tuder RM, Cool CD, Lynch DA, Flores SC, Voelkel NF. Endothelial cell death and decreased expression of vascular endothelial growth factor and vascular endothelial growth factor receptor 2 in emphysema. Am J Respir Crit Care Med. 2001;163(3 Pt 1):737-744.

39. Tsuji T, Aoshiba K, Nagai A. Alveolar cell senescence in patients with pulmonary emphysema. Am J Respir Crit Care Med. 2006;174(8): 886-893.

40. Henson PM, Vandivier RW, Douglas IS. Cell death, remodeling, and repair in chronic obstructive pulmonary disease? Proc Am Thorac Soc. 2006;3(8):713-717.

41. Hodge S, Hodge G, Holmes M, Reynolds PN. Increased airway epithelial and T-cell apoptosis in COPD remains despite smoking cessation. Eur Respir J. 2005;25(3):447-454.

42. Vandivier RW, Henson PM, Douglas IS. Burying the dead: the impact of failed apoptotic cell removal (efferocytosis) on chronic inflammatory lung disease. Chest. 2006;129(6):1673-1682.

43. Morel O, Toti F, Morel N, Freyssinet JM. Microparticles in endothelial cell and vascular homeostasis: are they really noxious? Haematologica. 2009;94(3):313-317.

44. Martinez MC, Tual-Chalot S, Leonetti D, Andriantsitohanina R. Microparticles: targets and tools in cardiovascular disease. Trends Pharmacol Sci. 2011;32(11):659-665.

45. Segura-Valdez L, Pardo A, Gaxiola M, Uhal BD, Becerril C, Selman M. Upregulation of gelatinases A and B, collagenases 1 and 2, and increased parenchymal cell death in COPD. Chest. 2000;117(3):684-694.

46. Kasahara Y, Tuder RM, Cool CD, Voelkel NF. Expression of 15-lipoxygenase and evidence for apoptosis in the lungs from patients with COPD. Chest. 2000;117(5 Suppl 1):260S.

47. Kasahara Y, Tuder RM, Taraseviciene-Stewart L, et al. Inhibition of VEGF receptors causes lung cell apoptosis and emphysema. J Clin Invest. 2000;106(11):1311-1319.
International Journal of COPD

\section{Publish your work in this journal}

The International Journal of COPD is an international, peer-reviewed journal of therapeutics and pharmacology focusing on concise rapid reporting of clinical studies and reviews in COPD. Special focus is given to the pathophysiological processes underlying the disease, intervention programs, patient focused education, and self management protocols.

\section{Dovepress}

This journal is indexed on PubMed Central, MedLine and CAS. The manuscript management system is completely online and includes a very quick and fair peer-review system, which is all easy to use. Visit http://www.dovepress.com/testimonials.php to read real quotes from published authors. 